\title{
SISTEM MONITORING DETAK JANTUNG BERBASIS LoRa
}

\author{
Rini Puji Astutik ${ }^{1)}$, Rendy Fadjar Bakti' ${ }^{2)}$ \\ 1,2) Jurusan Teknik Elektro- Universitas Muhammadiyah Gresik \\ 12astutik_rpa@umg.ac.id, ${ }^{2}$ rendyfajar23@gmail.com \\ JL. Sumatra No 101, Gresik 61121, Jawa Timur
}

\begin{abstract}
ABSTRAK
Jaringan sensor nirkabel yang diimplementasikan pada bidang kesehatan manusia merupakan teknologi yang krusial untuk melakukan monitoring kondisi dari seorang pasien khususnya orang tua. Banyak keadaan dari badan seorang pasien yang perlu untuk diawasi antara lain denyut nadi, suhu badan dan detak jantung. Selama ini keadaan tersebut dicatat secara berkala oleh seorang perawat yang bertugas sehingga memungkinkan data tidak dapat diketahui setiap saat. Dalam proposal ini dilakukan penelitian untuk membuat prototype perangkat sistem monitoring kesehatan pasien dengan menggunakan jaringan sensor nirkabel berbasis teknologi LoRa. Kesehatan dalam penelitian ini difokuskan pada monitoring detak jatung pasien sehingga jika terjadi kejanggalan pada detak jantung dapat diketahui secara otomatis waktu sebenarnya. Jaringan sensor nirkabel terdiri dari node-node yang mengumpulkan informasi detak jantung dari pasien dimana selanjutnya informasi tersebut dikirimkan ke node pusat. Node pusat dalam penelitian ini digunakan komputer (personal computer) untuk menampilkan sinyal detak jantung sebagai sistem monitoring. Pengiriman sinyal yang tertampil pada komputer dari node pasient menggunakan module radio frequency $(R F)$, dalam hal ini digunakan teknologi LoRa. Hasil pengukuran yang diperoleh kurang maksimal dikarenakan sensor yang digunakan kurang sensitive
\end{abstract}

Kata-kata kunci: Monitoring, LoRa, Jaringan sensor nirkabel, detak jantung, pasien.

\section{PENDAHULUAN}

Dalam rangka menuju revolusi industry 4.0, banyak teknologi yang telah dikembangkan dan salah satunya adalah jaringan sensor nirkable. Jaringan sensor nirkabel ini banyak digunakan dalam perangkat pintar seperti smart office, smart home, smart farming, smart city, smart healthcare dan lain sebagainya. Smart healthcare merupakan salah satu implemtasi dari jaringan sensor nirkable yang merupakan teknologi krusial. Seorang pasien dengan kondisi yang mengkawatirkan perlu dilakukan pemantauan kesehatan dimana selama ini dibanyak rumah sakit dilakukan pencatatan keadaan pasien secara berkala. Pencatatan secara berkala tidak mewakili keadaan setiap saat dari seorang pasien. Oleh sebab itu diperlukan suatu perangkat pemantauan pasien secara otomatis dan setiap saat sehingga jika terjadi sesuatu keganjilan maka dapat diketahui dengan segera.

Banyak penelitian yang telah
dilakukan dalam bidang monitoring kesehatan seperti pada [1] dan [2] yang membahas tentang sistem monitoring kesehatan pasien dengan menggunakan jaringan sensor nirkable berbasis teknologi Zigbee. Perangkat komunikasi Zigbee banyak digunakan pada jaringan sensor nirkable pada awalnya, namun saat ini sudah jarang digunakan dikarenakan jarak yang dicapai hanya kurang lebih $9 \mathrm{~m}$. Paper lain juga membahas tentang sistem monitoring kesehatan menggunakan jaringan sensor nirkabel namun berbasis GSM. [3] Teknologi GSM kurang efektif untuk jaringan sensor nirkabel dikarenakan perlu adanya kuota atau pulsa untuk melakukan 
komunikasi antar node. Penelitian tentang desiain rangkaian pengumpul data untuk jaringan sensor nirkable dengan mempergunakan teknologi WiFi juga dibahas pada [4]. Teknologi WiFi mempunyai jangkauan yang sama untuk Zigbee sekitar $10 \mathrm{~m}$, sehingga untuk rumah sakit yang luas kurang bisa maksimal dalam penggunaannya.

Dalam paper ini terbagi menjadi beberapa bagian. Bab 1 tentang latar belakang, bab 2 dasar teori penunjang, bab 3 desain perencanaan, bab 4 hasil dan diskusi dan terakhir bab 5 kesimpulan dan saran.

\section{DASAR TEORI}

\subsection{Jaringan Sensor Nirkabel}

Jaringan Sensor Nirkabel mempunyai roadmap dimana pengembangan jaringan ini pada beberapa bidang yang mungkin mengimplementasikan teknologi ini sangat berkaitan erat dengan kebutuhan manusia. Menurut [5], state of art dari jaringan sensor nirkabel dapat digambarkan seperti pada gambar 2.1.

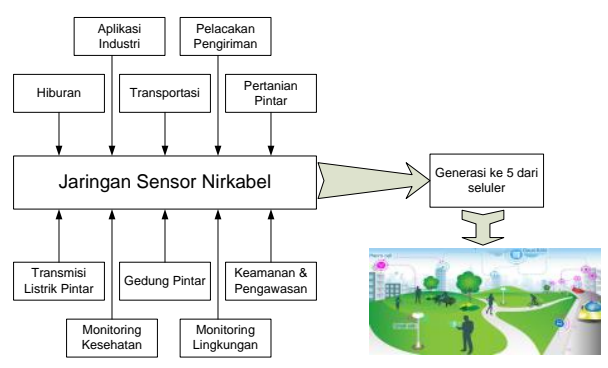

Gambar 1. State of Art dari Jaringan Sensor Nirkabel

$$
\text { Monitoring kesehatan yang }
$$
merupakan salah satu implementasi dari jaringan sensor nirkabel seperti pada [6] dimana digunakan WiFi sebagai komunikasi antara node arduino dan node MCU. Dalam rancangan ini, sistem dibedakan menjadi tiga bagian, yaitu bagian pertama yang berkaitan pengumpulan data kesehatan dari tiap pasien, kemudian bagian kedua proses pengirimaan data ke ruang monitoring dan bagian ketiga menghubungkan data di ruang monitoring ke internet untuk dapat digunakan oleh dokter atau perawat secara jarak jauh.

Dengan banyaknya penggunaan node dalam sebuah jaring sensor nirkabel maka tidak menutup kemungkinan terjadi salah pengertian diantara node dalam jaringan tersebut. Oleh karena itu diperlukan suatu kerja sama antar node untuk menjamin komunikasi dalam jaringan sukses. Selain itu memperluas cakupan area untuk sebuah jaringan sensor nirkable juga dibutuhkan sehingga dalam [7] dibahas penggunaan node koordinasi serta memperluas area cakupan dengan menggunakan Bluetooth sebagai perangkat komunikasi dari node pada pasien ke ruang monitor. Selain dari itu pengaturan penggunaan energy juga dibahas sehingga dicapai suatu sistem yang effisien.

Penggunaan LoRa sebagai perangkat komunikasi telah dibahas pada penelitian sebelumnya [8] dan diseminarkan dimana kemampuan LoRa diteliti secara mendalam baik secara simulasi maupun pengukuran real time. Dari penelitian diperoleh cakupan area untuk LoRa dengan model Dragino dapat mencapai $200 \mathrm{~m}$.

\subsection{Perhitungan Link Budget}

Perhitungan link budget adalah perhitungan pelemahan sinyal terhadap jarak sehingga pada jarak yang jauh kekuatan sinyal akan makin melemah. Dalam sistem komunikasi radio, perhitungan link budget diperoleh seperti pada persamaan (1) [9]

$P_{L}=|R S S I|+P_{t x}+G_{t x}+G_{r x}$

Dimana semua komponen dalam satuan $\mathrm{dB}$

$\mathrm{PL}=$ Redaman

RSSI $=$ Daya terima

Ptx = Daya pancar

Gtx = Penguat Pemancar

Grx = Penguat Penerima

Dengan mengetahui nilai komponen redaman dari log-distance maka nilai redaman dapat diperoleh dengan persamaan (2) $[10]$ 
$P_{L}=10 \times n \times \log _{10}(d)+P_{L_{0}}$

Dimana

$\mathrm{n}=$ komponen redaman

$\mathrm{d}=$ Jarak antara dua node yang berkomunikasi

$\mathrm{P}_{\mathrm{L} 0}=$ redaman yang terukur pada jarak yang pertama yang diperoleh dari persamaan (3)

$P_{L_{0}}=20 \times \log _{10}\left(\frac{4 \pi}{\lambda}\right)$

Dimana $\lambda$ adalah panjang gelombang dari sinyal yang digunakan sehingga dapat diperoleh dengan menentukan frekuensi yang digunakan.

\subsection{Unjuk Kerja Sistem dengan Perhitungan BER (Bit Error Rate)}

Perhitungan BER pada sistem komunikasi berdasarkan proses probabilitas dari banyaknya data yang diterima terhadap data yang dikirimkan. Berdasarkan [10] BER dipresentasikan dalam persamaan (4)

$B E R=\frac{\text { Data yang tidak diterima }}{\text { Total data yang terkirim }} \times 100 \%$

Dari persamaan 4 terlihat bahwa nilai BER yang lebih rendah mencerminkan sistem yang lebih baik

Pendekatan lain untuk menganalisa unjuk kerja teknologi LoRa yaitu dengan membandingkan waktu koheren $\left(\mathrm{T}_{\mathrm{c}}\right)$ dan waktu symbol $\left(\mathrm{T}_{\mathrm{s}}\right)$. Waktu koheren berbanding terbalik dengan perpindahan Doppler seperti dipresentasikan pada persamaan (5) [8]

$T_{c}=\frac{2 \pi}{\omega_{D}}$

Dimana

$\mathrm{T}_{\mathrm{c}}=$ Waktu koheren

$\omega_{\mathrm{D}}=$ Frekuensi anguler dari Doppler

Jika $T_{s}$ lebih besar dari $T_{c}$ maka fading cepat terjadi karena akibat Doppler yang menyebabkan penyimpangan sinyal (signal distortion). Waktu symbol dalam modulasi LoRa dapat dihitung seperti pada persamaan (6)
$T_{S}=\frac{2^{S F}}{B W}$

Dimana

$\mathrm{T}_{\mathrm{s}}=$ Waktu simbol

$\mathrm{SF}=$ Spreading Faktor

$\mathrm{BW}=$ Bandwith

\section{DESAIN SISTEM MONITORING DETAK JANTUNG}

\subsection{Perancangan Hardware}

Jaringan sensor nirkabel dalam penelitian ini akan dirancang 2 node sebagai pengindera dan 1 node sebagai pengumpul data dari kedua node pengindera dimana masing-masing node dilengkapai dengan perangkat komunikasi yaitu LoRa. Perancangan ini ditunjukkan seperti pada gambar 2

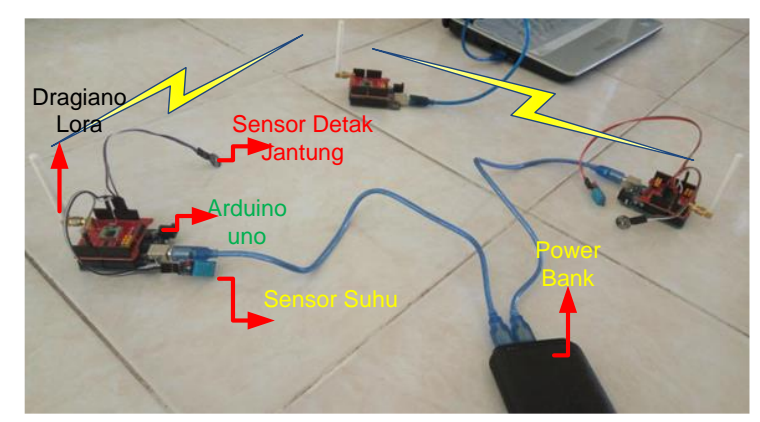

Gambar 2. Perancangan Hardware Sistem JSN

Setiap data yang diterima oleh masing-masing node akan dikumpulkan di node sink yaitu node pengumpul data dan ditampilkan di PC. Data ini untuk kemudian akan dibandingkan dengan data pengukuran dari aplikasi android yang sudah tersedia di HP android.

\subsection{Perancangan Software}

Perancangan perangkat lunak dalam hal ini untuk mengimplementasikan monitoring detak jatung pasien digambarkan pada gambar 3. Diawali dengan persiapan penginderaan detak jantung pada masingmasing node. Kemudian tiap-tiap node melakukan pengiriman data ke node pusat (cluster head) untuk ditampilkan pada PC secara bergantian antara node. 


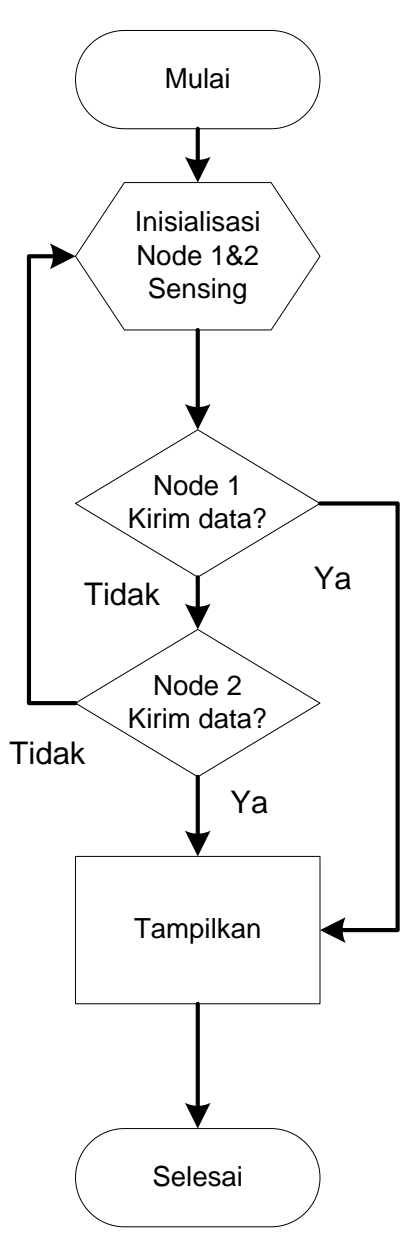

Gambar 3. Diagram Alir Sistem Monitoring Detak Jantung

\subsection{Perancangan Pengujian}

Selain pengukuran, dalam penelitian ini juga dilakukan simulasi sebagai perbandingan perhitungan secara real dan simulasi. Beberapa simulasi yang dilakukan dalam adalah sebagai berikut

- Pengujian link budget

- Pengujian kesalah pengiriman data (BER)

- Pengujian Efek Doppler

- Pengujian Detak Jantung

\section{HASIL DAN DISKUSI}

\subsection{Pengujian Link Budget}

Pengujian pertama dari penelitian ini adalah dengan melakukan pengukuran kekuatan sinyal (Signal Strength) dengan beberapa jarak yang berbeda. Dari hasil pengukuran kekuatan sinyal ini dan dibanding dengan perhitungan berdasarkan seperti pada persamaan (1-3) terlihat seperti gambar 4.

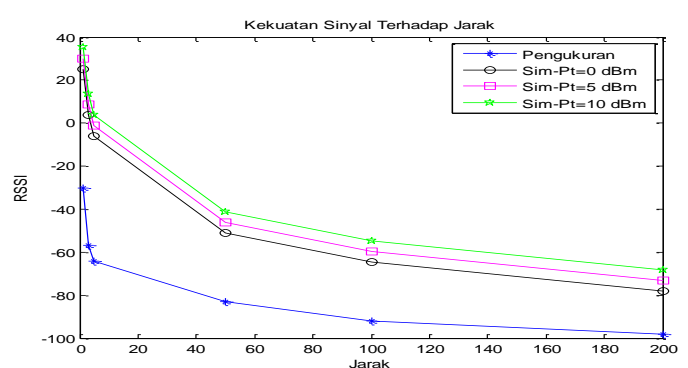

Gambar 4. Pengukuran dan Perhitungan Kekuatan Sinyal

Dari hasil pengukuran dan perhitungan dapat dilihat bahwa berdasarkan pengukuran kekuatan sinyal dari LoRa Dragino Shield akan menurun seiring dengan meningkatnya jarak antara dua node yang berkomunikasi. Sinyal terjelek yang diterima oleh node berdasarkan pengukuran adalah -98 dBm ketika jarak mencapai 200 $m$ seperti ditunjukan pada grafik warna biru.

Secara perhitungan dengan memilih beberapa parameter seperti gain pengirim dan penerima sebesar 1 sedangkan frekuensi yang digunakan adalah $915 \mathrm{MHz}$ seperti spesifikasi pada LoRa Dragino Shield yang digunakan. Untuk daya pancar dipilih tiga nilai yang berbeda yaitu $0 \mathrm{dBm}, 5 \mathrm{dBm}$ dan $10 \mathrm{dBm}$ dan hasilnya seperti pada grafik warna hitam untuk daya pancar sebesar 0 $\mathrm{dBm}$, warna magenta untuk daya pancar sebesar $5 \mathrm{dBm}$ dan untuk $10 \mathrm{dBm}$ dilukiskan dengan grafik warna hijau. Hasil simulasi memperlihatkan semakin tinggi daya pancar maka semakin baik kekuatan sinyal terima. Kekuatan sinyal terima terbaik dicapai ketika daya pancar yang digunakan adalah $10 \mathrm{dBm}$ yaitu $-68,17 \mathrm{dBm}$ pada jarak $200 \mathrm{~m}$.

\subsection{Pengujian Kesalahan Pengiriman Data}

Pengunjian kesalahan data berdasarkan persamaan (4) dengan melakukan percobaan pengiriman data antara dua node yang saling berkomunikasi. Pada pengujian ini dilakukan percobaan sebanyak 35 variasi jarak dengan perbedaan jarak sepanjang $1 \mathrm{~m}$ dan berdasarkan 
perhitungan diperoleh kesalahan pengiriman data seperti digambarkan seperti pada gambar 5 .

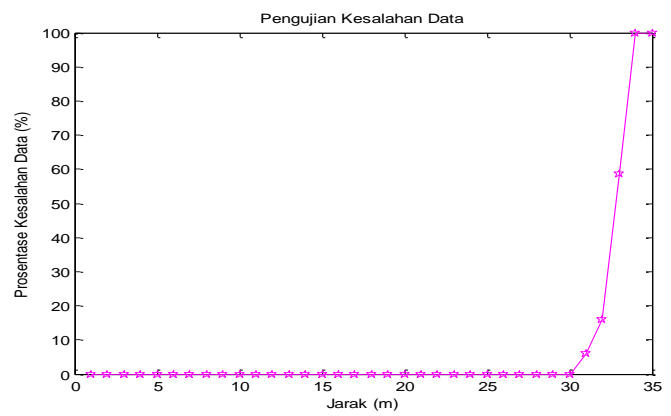

Gambar 5. Pengujian Kesalahan Pengirimana Data

Dari gambar 5 terlihat semakin jauh jarak komunikasi maka semakin besar prosentase kesalahan pengirimana data. Terlihat dari jarak $31 \mathrm{~m}$ maka sudah terjadi kesalahan dengan prosentase rata-rata sebesar 6\% dan sejak jarak $34 \mathrm{~m}$ maka tidak ada data yang diterima sehingga prosentasi rata-rata kesalahan pengiriman data sebesar $100 \%$.

\subsection{Pengujian Efek Doppler}

Efek Doppler merupakan salah satu gangguan pada sistem komunikasi nirkabel dimana hal ini akan terjadi jika waktu simbol melebihi waktu koheren. Dalam perhitungan ini disetting nilai Spreading Factor dan Bandwidth yaitu $\mathrm{BW}=125 \mathrm{kbps}$ dengan $\mathrm{SF}=12, \quad \mathrm{BW}=125 \mathrm{kHz}$ dengan $\mathrm{SF}=11$, $\mathrm{BW}=125 \mathrm{kHz}$ dengan $\mathrm{SF}=10$ dan $\mathrm{BW}=250$ $\mathrm{kHz}$ dengan $\mathrm{SF}=7$. Hasil perhitungan diperoleh data seperti digambarkan pada gambar 6

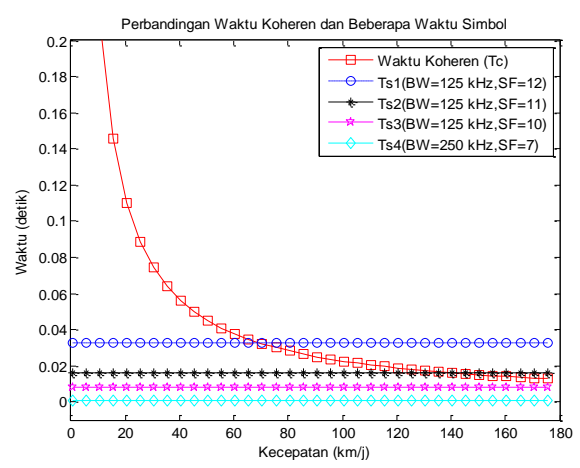

Gambar 6. Pengujian Efek Doppler
Dari gambar 6 terlihat bahwa ketika nilai SF tinggi maka kecepatan tinggi akan menyebabkan terjadinya efek Doppler. Ketika $\mathrm{SF}=12$ dan bandwidth $125 \mathrm{kHz}$ maka efek Doppler terjadi saat kecepatan lebih dari $70,5 \mathrm{~km} / \mathrm{jam}$. Namun saat $\mathrm{SF}=7$ dengan bandwidth $250 \mathrm{kHz}$ dan $\mathrm{SF}=10$ dengan bandwidth $125 \mathrm{kHz}$ maka waktu koheren selalu berada diatas waktu simbol. Hal ini berarti untuk parameter tersebut efek Doppler tidak akan pernah terjadi.

\subsection{Pengujian Detak Jantung}

Data diambil dari dua sistem yaitu perangkat jaringan sensor nirkabel dan aplikasi instance heart rate. Pengujian dari sistem monitoring detak jantung dan aplikasi android ditunjukkan seperti pada gambar 7
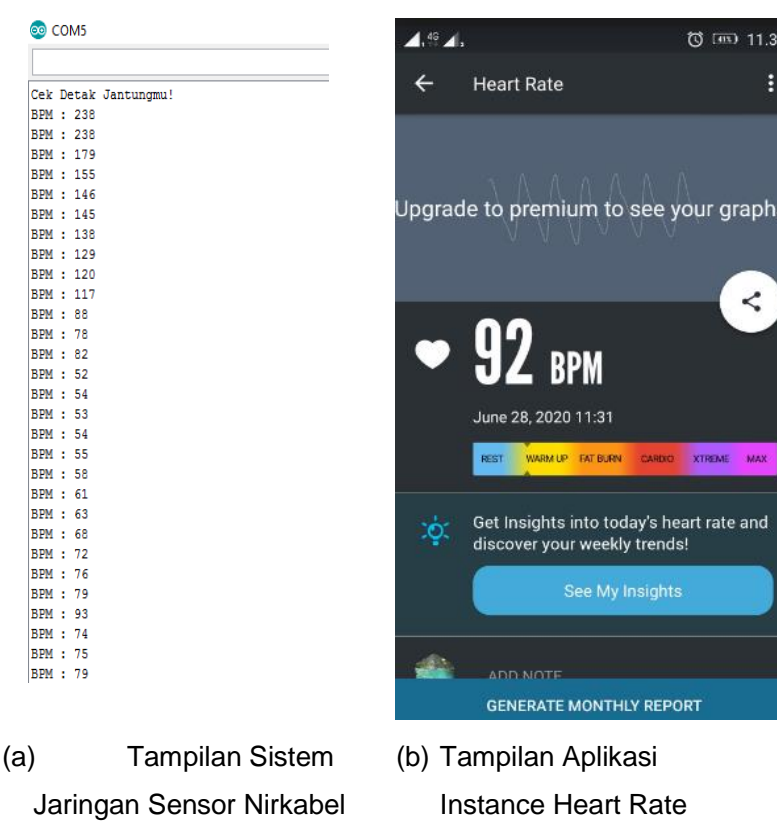

(b) Tampilan Aplikasi

Instance Heart Rate

Gambar 7. Pengukuran dari Sistem JSN dan Aplikasi dari Pasien

Tabel 1 menunjukkan pengukuran dari beberapa responden baik dari sistem jaringan sensor nirkabel dan aplikasi android. Dari hasil terlihat bahwa tidak ada perbedaan hasil pengukuran dari sistem jaringan sensor nirkabel antara yang berusia muda dan senja. Hal ini dikarenakan spesifikasi sensor pulsa kurang bisa mengakomodasi secara detail sehingga pengukuran kurang bisa menampilkan hasil yang sebenarnya. Penggantian sensor yang lebih mempunyai 
spesifikasi khusus untuk medis akan mendapatkan hasil yang maksimal.

Tabel 1 Pengukuran Detak Jantung dari Beberapa Responden

\begin{tabular}{lllll}
\hline No & Responden & Usia & JSN & Aplikasi \\
\hline 1 & A & 45 & 191 & 114 \\
\hline 2 & B & 35 & 79 & 92 \\
\hline 3 & C & 70 & 144 & 120 \\
\hline 4 & D & 18 & 90 & 87 \\
\hline 5 & E & 32 & 80 & 84 \\
\hline 6 & F & 38 & 85 & 90 \\
\hline
\end{tabular}

\section{KESIMPULAN}

Sistem monitoring detak jantung memerlukan komponen dengan sensitifitas tinggi. Dari hasil percobaan dan simulasi dapat disimpulkan sebagai berikut:

- Simulasi dari Pemodelan Sistem

- Pengukuran berdasarkan percobaan dengan menggunakan LoRa Dragino Shield menghasilkan kekuatan sinyal terima terjelek adalah $-98 \mathrm{dBm}$ pada jarak $200 \mathrm{~m}$. sedangkan berdasarkan perhitungan diperoleh $-68,17 \mathrm{dBm}$ pada jarak $200 \mathrm{~m}$ dengan daya pancar digunakan sebesar $10 \mathrm{dBm}$.

- Kesalahan pengiriman data juga dilakukan pengujian sebanyak 35 variasi jarak dengan perbedaan jarak sepanjang $1 \mathrm{~m}$ dan hasilnya adalah jarak maksimum untuk pengiriman data adalah $34 \mathrm{~m}$ dimana prosentase kesalahan terjadi hingga $100 \%$.

- Pengujian efek Doppler menghasilkan bahwa efek Doppler terjadi ketika $\mathrm{SF}=12$ dan bandwidth $125 \mathrm{kHz}$ pada saat kecepatan melebihi 70,5 km/jam. Efek Doppler ini tidak terjadi pada waktu $\mathrm{SF}=7$ dengan bandwidth 250 $\mathrm{kHz}$ dan $\mathrm{SF}=10$ dengan bandwidth sebesar $250 \mathrm{kHz}$ karena waktu simbol tidak pernah melebih waktu koheren

- Penggunaan sensor pulsa kurang dapat menampilkan hasil yang sesuai dengan actual, hal ini dapat dilihat dari table 1 dimana antara responden usia lanjut dan muda tidak ada bedanya.

\section{Daftar pustaka}

[1] M.Raste, S.K.Parchandekar, G.S.Wagh,"Wireless Sensor Network For Patient Health Monitoring System", International Research Journal of Engineering and Technology, Vol.4, Issue 6, June 2017.

[2] T S Sollu, Alamsyah, M.Bachtiar and A G Sooai,'Patients' Heart Monitoring System Based on Wireless Sensor Network", International Conference on Vocational Education and Electrical Engineering, 2018.

[3] Sunil L. Rahane, Prof.Ramesh S. Pawase, "A Healthcare Monitoring System Using Wireless Sensor Network with GSM", International Journal of Advanced Research in Electrical, Electronics and Instrumentation Engineering,Vol.4 Issue. 7, July 2015.

[4] Giang N.Tran, Linh H.Truong, Hoa T.Tran, and Minh T.Nguyen, "A Design of Sensing Data Collection Circuits for Wireless Sensor Network Utilizing WiFi Technology", International Computer Science and Engineering Society, Vol.5, No.1, March 2019.

[5] Rahat Ali Khan and Al-Sakib Khan Pathan,"The state-of-the-art wireless body area sensor networks: A survey",International Journal of Distributed Sensor Networks, March 2018

[6] Uttara Gogate and Jagdish Bakal,'Healthcare Monitoring System Based on Wireless Sensor Network for Cardiac Patients", Biomedical \& Pharmacology Journal, Vol. 11(3), September 2018.

[7] Er.Perumal Sindhu rekha.G, Hindhu shree.S, Rameena.S, Hemalatha.B, 
Anletpamila suhi.P,"A Hospital Healthcare Monitoring System Using Wireless Sensor Networks", International Conference on Emerging trends in Engineering, Science and Sustainable Technology, 2017.

[8] Rini Puji Astutik and Hendra Ari Winarno,"Feasibility Test on the Performance of LoRa Technology Incorporated in the Wireless Sensor Networks", International Conference on Engineering and Applied Technolgy, October 2019

[9] Achmad Fauzi Rachmani and Fitri Yuli Zulkifli, "Trial and Evaluation of LoRa Performance For Smart System MultiClient Model," in International Seminar Intelligent Technolgy on Its Application, Denpasar, Bali, August 2018, pp. 33-38

[10] Misbah et al., "Communication System on Wireless Sensor Networks using Rasberry Pi and Arduino for Monitoring Gas of Air Pollution," in Internationl Seminar Intelligent Technology on Its Application, Denpasar, Bali, 44, p. 39 